\title{
Psychological utility of art therapy for patients with advanced cancer
}

\author{
Michiyo Ando ${ }^{1 *}$ and Shigeru Hayashida ${ }^{2}$ \\ ${ }^{1}$ St. Mary's College, Japan \\ ${ }^{2}$ Naito Hospital, Japan
}

\begin{abstract}
Patients with advanced cancer experience various kind of suffering such as physical pain, psychological suffering, or existential suffering. Art therapy is one of the most effective psychological cares. The aim of this study was to investigate the psychological utility of art therapy for patients with advanced cancer. Eight patients with advanced cancer received art therapy with an art therapist from two to four times in a general hospital. They made art including drawing pictures or making collages to express their feelings and thoughts. Each patient explained his art after each session and discussed changes that they had undergone between sessions. The therapist wrote down patients' words including explanation toward arts, their emotions, and thoughts, then categorized to evaluate the utility of the art therapy, and the following categories emerged: "Promotion of communication with other patients," "Promotion of communication with family members," Hope for the future," Making psychological space to forget illness," "Missing the good old times," and "Relaxation." These results suggest that art therapy has psychological utility for patients with advanced cancer such as promoting communication, finding hopes for the future, and adapting to life in the hospital.
\end{abstract}

\section{Introduction}

Distress related to cancer diagnosis and treatment is explicitly tied to a number of common practical, physical, and psychological problems [1]. Depression and anxiety are common among patients receiving palliative care and contribute to a greatly diminished quality of life [2]. Moreover, since cancer is a primary cause of death, cancer patients may also experience existential suffering or spiritual pain such as loss of meaning to live or purpose, loss of relationships with important persons, or loss of a relationship with a transcendent-like God. Particularly in cases of advanced cancer or recurrence, patients are confronted with the reality of death. Religion and spirituality are important dimensions of most patients' experiences of advanced illness [3].

Art therapy is an effective intervention for psychological and spiritual care, and has been reported to be effective for alleviation of anxiety, depression, and somatic symptoms for women with breast cancer [4] and for tension, depression, anger, confusion, and vigor [5]. In a systematic review of creative psychological interventions including art therapy, music therapy, dance therapy and movement therapy, Archer et al. [6] found benefits for anxiety and depression, quality of life, coping, stress, anger and mood. Similarly, Bozcuk et al. [7] showed that a painting art therapy program improved quality of life and depression in cancer patients receiving chemotherapy.

Many studies have investigated the effects of art therapy on mental and psychological conditions such as depression, anxiety, and symptoms of well-being measured by scales, but other utility that are difficult to measure objectively were not examined. In performing art therapy, we have observed and heard behavior related to psychological utility of clinical situations, and we wanted to examine these points. Psychological refers to psychological and social issues, including interactions between a person and their environment. Therefore, the aim of this study was to examine the psychological utility of art therapy for patients with advanced cancer.

\section{Methods}

\section{Participants}

The participants were 8 patients ( 1 male, 7 females) with advanced cancer (metastatic and stage IV) in a general hospital in western Japan (Table 1). The inclusion criteria were cancer in advanced stage IV, ability to communicate, and age $>20$ years. The exclusion criteria were severe pain or physical symptoms diagnosed by the primary physician, and cognitive impairment such as dementia or serious mental illness. Performance status (PS) was measured by the Eastern Cooperative Oncology Group Performance Status Rating (ECOG-PSR), which is a single item rating of five activity levels from 0 (fully active) to 4 (completely disabled) [8].

Table 1. Background of participants

\begin{tabular}{|c|c|c|c|c|c|}
\hline ID & Gender & Age & Stage & PS & Married \\
\hline 1 & Female & $60 \mathrm{~s}$ & IV & 4 & Yes \\
\hline 2 & Female & $40 \mathrm{~s}$ & IV & 2 & Yes \\
\hline 3 & Male & $40 \mathrm{~s}$ & IV & 2 & No \\
\hline 4 & Female & $30 \mathrm{~s}$ & IV & 4 & No \\
\hline 5 & Female & $40 \mathrm{~s}$ & IV & 2 & Yes \\
\hline 6 & Female & $50 \mathrm{~s}$ & IV & 2 & Yes \\
\hline 7 & Female & $60 \mathrm{~s}$ & IV & 2 & Yes \\
\hline 8 & Female & $50 \mathrm{~s}$ & IV & 3 & Yes \\
\hline
\end{tabular}

Correspondence to: Michiyo Ando, St. Mary's College, Faculty of Nursing, Tsubuku Honmachi 422, Kurume city, Fukuoka, Japan, Tel: +81-942-50-0744; Fax: +81-942-34-9125; E-mail: andou@st-mary.ac.jp

Key words: art therapy, patients, advanced cancer, utility, psycho-social

Received: September 07, 2017; Accepted: September 26, 2017; Published: September 28, 2017 


\section{Procedure}

After getting informed consent, the art therapist visited the patient, and conducted the art therapy. In the art therapy, there were from two to four sessions of $1 \mathrm{~h}$ each individually. An art therapist who was certified in Japan conducted the therapy. In the first session, patients talked about their emotions or thoughts of their illness with the therapist. They then made art items using clay, collage (fancy paper, felt glue sticks, magazines), drawing (color pencils, pastel chalk, pencils), and a sketch book. After making the art, the patients explained its meaning. One week later, in the second session, the patients narrated changes that had occurred over the week, and then made and explained further art items. The therapist wrote down patients' words including explanations toward arts, emotions, thought, and changes.

\section{Ethical consideration}

The ethical review board at St. Mary's College, Fukuoka, Japan approved the study. The hospital oncologist recruited patients with various types of advanced cancer and obtained initial informed consent after explaining the study. If a patient agreed to participate, the physician referred the patient to the therapist, who then explained the study to the patient in more detail. Those who agreed to participate gave signed informed consent.

\section{Analysis}

Patients' words including explanations toward arts, emotions, thought, and changes were summarized. Their words were relatively short, and therefore we did not conduct a qualitative analysis. Instead, we summarized their words in to categories to maintain reliability and validity, researchers discussed categories to obtain agreement and asked professional researcher about palliative care to confirm this categorization.

\section{Results}

The categories established from description of patient's words and of the interviewer's observation are summarized (Table 2).

Patient ID1 was a woman with advanced stage cancer who liked art and looked forward to make art. In the first session, she made a collage. She explained that it was her hope to go on a nature trip (1. Hope for the future). "I walk, go to a spring, ride on a train, get to the top of a mountain, and see the sea. The art is a story of the trip. When I see this picture, I become relaxed (2. Relaxation)." In the second session, she drew a pattern. She explained, "When I saw a ceiling, the pattern looked like faces. In the picture, I have drawn patients' faces (Figure 1). They are all friends who fight against illness. So I connected the faces. When I was drawing the figure, other patients came to see it and we shared our feelings and talked about various things (3. Promotion of communication with other patients)." In the third session, she made a collage of flowers. The patient's husband added more flowers and her daughter talked about the flowers (4. Promotion of communication with family members).

Patient ID 2 was a woman in her $30 \mathrm{~s}$. She liked beautiful things and her nails were decorated by her daughter. She drew flowers in the garden and was relaxed (5. Relaxation).

Patient ID3 was a man whose job had been as a designer. He missed the old days and drew a figure smoothly. He said that "I will begin to draw picture again (6. Hope for the future)."

Patient ID4 was a woman with severe difficulty with breathing. However, she wanted to participate in the session because it focused her attention on the artwork and helped her to forget her severe illness (7. Making psychological space to forget illness). She drew a picture about driving with her mother. She made a collage with help from the interviewer. She enjoyed the pictures with her sweet memories, and her mother saw it and shared their memories (8. Promotion of communication with family members).

Patient ID5 had experienced long-term medical treatment, and she talked about the pain of treatment with the counselor. She drew a picture of fruits because she drew such pictures in her previous work. She painted colors to focus her attention on the picture. She said that "I focus on painting colors to forget illness (9. Making psychological space to forget illness).

Patient ID6 had come to the hospital from her distant home town. Her husband and mother had both died in the previous year. She loved a pet dog and she drew a picture of the dog in the first session. She and the counselor talked about the pet and she was strengthened and lively (10. Promoting patients' likes and cheering up). In the next session, she made a collage of food that she wanted to eat. Other patients agreed with her feelings and talked to each other (11. Promotion of communication with other patients). After the session, she talked about her hopes for the future, such as going to a concert and hot springs (12. Hope for the future).

Patient ID7 also liked a pet dog. Her pet dog had died and she remembered it when she found a similar photograph during the art making. She made a collage of the pet and missed the old days (13. Relaxation).

Patient ID8 used to go to foreign countries for sightseeing when she was well. She talked a lot about her tours. In the art making, she expressed missing the old times of nature scenes (14. Missing old times). After the session, she expressed hope that in the future she wanted to eat pasta in an Italian restaurant and to go to sightseeing to see cherry trees (Figure 2) (15. Hope for the future).

\section{Discussion}

Our results suggest that art therapy has utility for "Promotion of communication with other patients" "Promotion of communication with family members," "Hope for the future," "Making psychological space to forget illness," "Promoting patients' likes and cheering up," and "Relaxation."

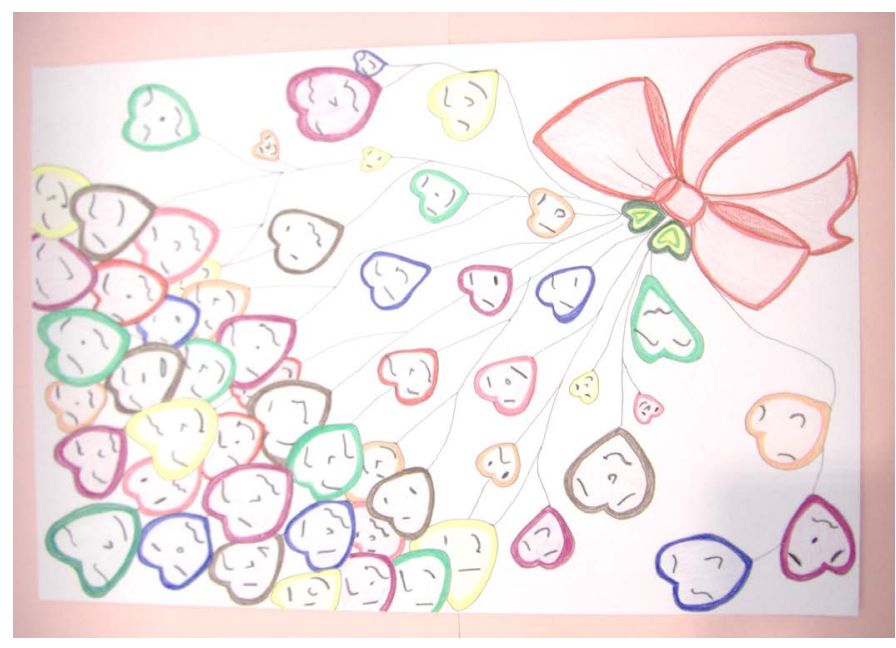

Figure 1. The art of patient ID1 (Faces of Patients) 
Table 2. Psychological utility of art therapy deduced from words.

\begin{tabular}{|c|c|c|}
\hline ID & Description from patients' words & Psychological utility \\
\hline ID1 & $\begin{array}{l}\text { - She liked art. She made a collage of a nature trip (Figure 1). This was her hope. "I am relaxed." } \\
\text { - She talked about the figure with other patients peacefully. She drew a ceiling pattern of faces (Figure 2). } \\
\text { - In the } 3^{\text {rd }} \text { session, she drew a flower and her family added some leaves. The patient and family members } \\
\text { talked about art. }\end{array}$ & $\begin{array}{l}\text { 1. Hope for the future } \\
\text { 2. Relaxation } \\
\text { 3. Promotion of communication with other patients. } \\
\text { 4. Promotion of communication with family members }\end{array}$ \\
\hline ID2 & - She liked beautiful things. She drew flowers in the garden. & 5. Relaxation \\
\hline ID3 & $\begin{array}{l}\text { - The man drew a picture. His previous job was a designer. } \\
\text { "I will begin to draw picture again." } \\
\text { He also missed the old days. }\end{array}$ & 6. Hope for the future \\
\hline ID4 & $\begin{array}{l}\text { - She was not very well physically. However, she wanted to draw a picture. She also wanted to make a collage. } \\
\text { She missed happy days with her mother. } \\
\text { - Her mother also missed seeing her art. }\end{array}$ & $\begin{array}{l}\text { 7. Making psychological space to forget illness } \\
\text { 8. Promotion of communication with family members }\end{array}$ \\
\hline ID5 & $\begin{array}{l}\text { - She was a teacher in a nursery home, and remembered that time and drew fruits. She said, "I can focus my } \\
\text { attention on drawings. It is good for me to forget illness." }\end{array}$ & 9. Making psychological space to forget illness \\
\hline ID6 & $\begin{array}{l}\text { - She had lost her husband and her mother in a year. So she had been shocked. She made a collage about } \\
\text { delicious food because her food types were strictly limited. } \\
\text { - Staffs and visitors talked with the patients about her delicious food art. } \\
\text { - She expressed her hopes to eat it and go to a concert. }\end{array}$ & $\begin{array}{l}\text { 10. Promoting patients' likes and cheering up } \\
\text { 11. Promotion of communication with others } \\
\text { 12. Hope for the future }\end{array}$ \\
\hline ID7 & - She loved a pet dog. So she made a collage about the pet frequently. She miss the old days. & 13. Relaxation \\
\hline ID8 & $\begin{array}{l}\text { - She loved to go on trips. First she remembered the good old times and drew a picture of nature. } \\
\text { - Next session, she drew a picture of cherry blossoms that she hoped to see in the near future (Figure 2). }\end{array}$ & $\begin{array}{l}\text { 14. Missing old times } \\
\text { 15. Hope for the future }\end{array}$ \\
\hline
\end{tabular}

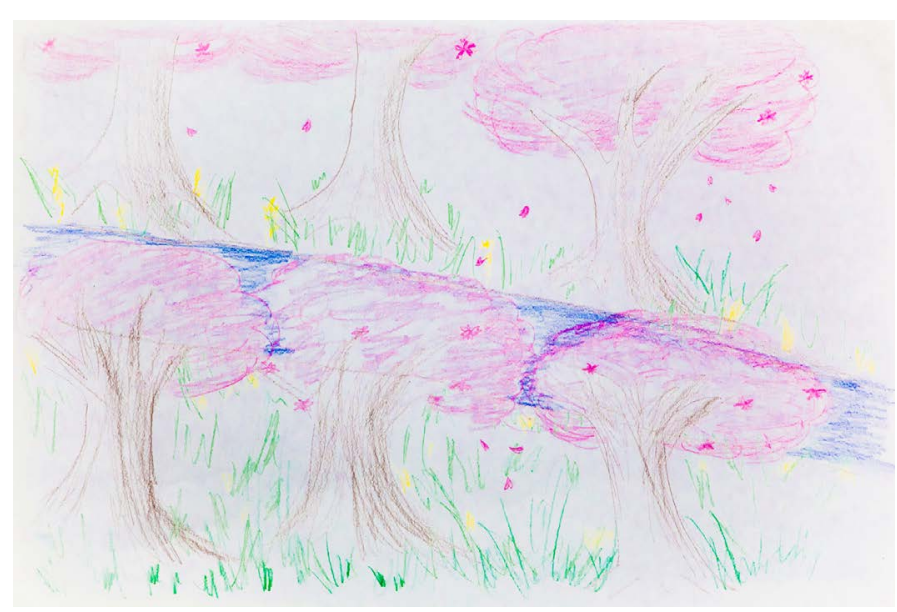

Figure 2. The art of patient ID8 (Waiting for Cherry Blossoms)

Forzoni et al. [9] identified aspects of how patients with cancer experience art therapy as being "effective," and showed therapeutic relationships allowing communication about oneself while feeling listened to. Luzzatto [10] also showed effectiveness of communication between the therapist and patients during art therapy. Our results add that art therapy promotes communication among patients and with family members". The patients in this study talked about their feelings freely and communicated their intention to cope with medical treatment and cancer.

The process of "Making psychological space to forget illness" may be similar to an aspect of mindfulness-based art therapy. Since patients with advanced cancer often experience existential suffering and do not have peace of mind, focusing on drawing to forget illness may be important for maintenance of their quality of life. This effect supports the findings of Boehm et al. [11], which showed the importance of expression of emotions. The process of focusing attention on drawing may be similar to that in mindfulness-based art therapy described by Monti et al. [12].

Regarding "Hope for the future," a previous case study by Vela $e t$ al. [13] demonstrated the effectiveness of art therapy through a creative journal arts therapy treatment program for female survivors of close partners. This suggested that art therapy is effective for promoting the hopes of people. In the present study, art therapy also seemed to be effective for elevating the hopes of patients with advanced stage cancer. Such patients are frequently limited in their food intake and by low physical strength or medical treatments. The patients miss the good times when they were well, and they desire to get back their life and have hope for the future. They sometimes express their hopes for the future, and art therapy promotes this behavior and may facilitate readjustment [14].

These results newly demonstrate that art therapy has psychological utility for patients with advanced cancer, in addition to having effects on depression, anxiety, and quality of life. We note some limitations in the study, including the small number of participants. There is a need to include many more participants to generalize the findings and to collect objective evidence to confirm the results.

\section{References}

1. Carlson LE, Waller A, Mitchell AJ (2012) Screening for distress and unmet needs in patients with cancer: review and recommendations. J Clin Oncol 30: 1160-1177. [Crossref]

2. Wilson KG, Chochinov HM, Skirko MG, Allard P, Chary S, Gagnon PR, Clinchi JJ (2007) Depression and anxiety disorder in palliative cancer care. J Pain Symptom Manage 33: 118-129.

3. Alcorn, SR, Balboni, MJ, Prigerson, HG, Reynolds, A, Phelps, AC, Wright, AA, Block, SD, Peteet, JR, Kachnic, LA, Balboni, TA (2010) If God wanted me yesterday, I wouldn't be here today. Religious and spiritual themes in patients' experiences of advanced cancer. J Palliat Med 13:581-588.

4. Thyme KE, Sundin EC, Wiberg B, Oster I, Astrom S, Lindh J (2009) Individual brief art therapy can be helpful for women with breast cancer: A randomized controlled clinical study. Palliat Support Care 7: 87-95.

5. Ando M, Imamura Y, Kira H, Nagasaka T (2013) Feasibility and efficacy of art therapy for Japanese cancer patients: a pilot study. The Arts in Psychotherapy 40: 130-133

6. Archer S, Buxton S, Sheffield D (2015) The effect of creative psychological interventions on psychological outcomes for adult cancer patients: a systematic review of randomized controlled trials. Psychooncology 24: 1-10

7. Bozcuk H, Ozcan K, Erdogan C, Mutlu H, Demir M, et al. (2017) A comparative study of art therapy in cancer patients receiving chemotherapy and improvement in quality of life by watercolor painting. Complement Ther Med 30: 67-72. [Crossref]

8. Oken MM, Creech RH, Tormey DC, Horton J, Davis TE, et al. (1982) Toxicity and response criteria of the Eastern Cooperative Oncology Group. Am J Clin Oncol 5: 649655. [Crossref] 
9. Forzoni S, Perez M, Martignetti A, Crispino S (2010) Art therapy with cancer patients during chemotherapy sessions: an analysis of the patients' perception of helpfulness. Palliat Support Care 8: 41-48

10. Luzzatto P (2010) Art Therapy. In: Holland JC (ed) Psycho-Oncology, Oxford University Press, Oxford, pp 422-424

11. Boehm K, Cramer H, Staroszynski T, Ostermann T (2014) Arts therapies for anxiety, depression, and quality of life in breast cancer patients: a systematic review and metaanalysis. Evid Based Complement Alternat Med 2014: 103297.
12. Monti DA, Peterson C, Kunkel EJS, Hauck WW, Pequignot E, Rhodes L, Brainard GC (2006) A randomized, controlled trial of mindfulness-based art therapy (MBAT) for women with cancer. Psychooncology 15:363-373.

13. Vela JC, Ikonomopoulos J, Dell'Aquila J, Vela P (2016) Evaluating the impact of creative journal art therapy for survivors of intimate partner violence. Counsel Outcome Res Eval 7: 86-98

14. Wood MJ, Molassiotis A, Payne S (2011) What research evidence is there for the use of art therapy in the management of symptoms in adults with cancer? A systematic review. Psychooncology 20:135-145.

Copyright: (C2017 Ando M. This is an open-access article distributed under the terms of the Creative Commons Attribution License, which permits unrestricted use, distribution, and reproduction in any medium, provided the original author and source are credited. 